\title{
Impact of writing workshops on doctoral student wellbeing
}

\section{Charles A. Buckley}

University of Liverpool

\section{Eli R. Saetnan}

University of Liverpool

\section{Amelia Gerber}

University of Liverpool

\section{Joanna Cheetham}

University of Liverpool

Thomas A. R. Price

University of Liverpool

Jenna Kenyani

University of Liverpool

\section{Alan M. Greaves}

University of Liverpool

\section{Abstract}

Few interventions addressing student wellbeing have been designed or evaluated specifically with doctoral students in mind despite the doctoral experience being distinct from that of other students. We therefore explore the benefits of interventions designed specifically to address a key source of stress or anxiety for doctoral students, namely thesis writing.

This research uses a mixed-methods approach to explore the ways in which doctoral thesis writing support sessions, in the form of writing workshops or writing retreats, can reduce the stress and anxiety associated with thesis writing specifically or academic writing more generally. Firstly, we quantified the reduction in writing related stress and anxiety associated with workshop participation using a survey completed before and after workshop attendance. Subsequently, we gathered student experiences of workshop participation through focus group interviews. 
Survey responses showed a clear reduction in participants' levels of stress and anxiety related to thesis writing and focus group respondents described many clear benefits of participating in writing support sessions. We conclude that participation in thesis writing workshops and writing retreats is a valuable strategy for reducing stress and anxiety associated with thesis writing. The sense of empowerment and confidence that comes from discussing thesis writing in a supportive environment with others in the same situation, and the opportunity to experiment with new tools and strategies, is very valuable for improving the wellbeing of doctoral students.

Keywords: doctoral students; stress; anxiety; wellbeing; thesis writing; writing workshops; writing retreats.

\section{Introduction}

Student wellbeing is of serious concern, with higher rates of stress and anxiety recorded among doctoral students than among other comparable populations (Hargreaves et al., 2014; Panger, 2015; Guthrie et al., 2017; Levecque et al., 2017; Evans et al., 2018; Metcalfe, Wilson and Levecque, 2018). Yet strategies that are specifically designed for doctoral students that support mental health and wellbeing are somewhat lacking across the sector (Metcalfe, Wilson and Levecque, 2018). The approaches to wellbeing support offered by universities for doctoral students are typically similar to those offered for undergraduates; the underlying assumption is that what works for undergraduate students will also work for doctoral students. However, the experiences of doctoral students are distinct from those of undergraduates and their wellbeing challenges are likely to reflect this (Hunter and Devine, 2016). Mackie and Bates (2019) therefore recommend better alignment between proposed interventions and the distinct challenges that occur during doctoral studies and indeed a number of projects addressing this issue have recently been established (Vitae, 2020).

Thesis writing is one such distinct doctoral level experience that both impacts on, and is impacted by, mental wellbeing. Wellbeing is not easily measurable, nor clearly defined in an academic context, though can at least in part be thought of as the absence of damaging levels of mental or physical stress (Muurlink and Poyatos Matas, 2011). In this 
study, we consider mental wellbeing as the antithesis of such stress or anxiety. Doctoral students (and their supervisors) are under increasing pressure from funders and universities to complete their theses on time, publish in high-ranking academic journals, and communicate to non-specialists via social media as expert contributors to public debates. Doctoral students therefore must successfully make the transition from novice to expert within a short time frame, and this process is often unclear, leading to a sense of stress and anxiety associated with the writing process. Poor mental wellbeing can in turn lead to poor productivity and lower levels of commitment to research (Guthrie et al., 2017) with over $75 \%$ of doctoral students in UK universities completing their thesis later than expected (HEFCE, 2010).

Learning academic writing is particularly challenging because it requires adopting tacit and implicit knowledge which extends across different disciplinary practices making academic writing extremely hard to share and to teach (Lonka, 2003; Starke-Meyerring, 2011). Negotiating this thesis writing journey elicits strong emotions, both positive and negative, which contribute to feelings of stress and anxiety (Wellington, 2010; Stubb, Pyhältö and Lonka, 2012) thereby impacting on the mental wellbeing of doctoral students. Supporting doctoral students through this challenging process is therefore key to both improving wellbeing and improving outcomes.

Often, writing support offered by universities is focused on the explicit and technical aspects of writing (e.g. Burgoine et al., 2011; Ciampa and Wolfe, 2019). Such technical instruction is addressing the final product of the thesis and may reduce some anxiety students have by improving their perception of their own technical skills (Samuels, Deane and Griffin, 2012; Foot, 2017; Crisfield, 2020). However, writing is a complex activity tied to changing social, cultural, and disciplinary discursive practices (Badenhorst, 2018) and learning to write in context is an ongoing endeavour (Lea and Street, 2006). Doctoral students benefit from support which emphasises thesis writing as an ongoing developmental and dialogic process through peer review and discussion across disciplinary boundaries (Delyser, 2003; Aitchison, 2009; Johnson, 2018), empowering them to negotiate their own thesis writing journey, and to handle the inevitable challenges along the way. 
Empowering students in this way, by focusing on process rather than product, leads to higher levels of wellbeing (Stubb, Pyhältö and Lonka, 2012). Some have examined longer term writing groups for their role in reducing writing anxiety, suggesting that such interventions can enhance student confidence (Ferguson, 2009; Fergie et al., 2011; Oluwole et al., 2018). The support of the group boosts students' perceptions of motivation and productivity (Noone and Young, 2019) by giving members of the group a sense of community (Aitchison and Lee, 2006) and peer support (Fergie et al., 2011; Tyndall et al., 2019). By opening up discussions with fellow writers, participants develop their own academic literacy and identity (Boud and Lee, 2007; Cuthbert, Spark and Burke, 2009; Mantai, 2017; Papen and Theriault, 2018) further building confidence. Similarly, writing retreats provide community support and are valued for the pleasure of sharing a room with other writers, and for the opportunity to talk about writing practices and experiences, as well as for task-focused time to write (Paltridge, 2016; Noone and Young, 2019). This community support provides both a social and emotional benefit, reducing the anxiety and stress associated with writing (Maher et al., 2008; Beasy et al., 2020).

Most research to date has focused on the impact of long-term writing programmes or intensive writing courses (e.g. Bærenholdt et al., 2010; Fergie et al., 2011; Wilmot, 2018); however, little evidence is available for the benefit of brief writing interventions which typically form part of central skills provision at UK universities. To gain insights into what might constitute suitable pedagogical approaches or to evidence the value of different adopted interventions, it is vital to examine the students' experiences of them (Cotterall, 2011). For this reason, we decided to evaluate the impact of a series of short writing support workshops that were developed to support doctoral students at our UK researchintensive university by exploring the student experience of participating in these sessions.

\section{Methodology and methods}

The lack of writing support specifically aimed to support doctoral students had been noted as a concern at our institution. At the same time, the institution has become aware of growing concern for the wellbeing of this group of students. As a result, a programme of workshops to address thesis writing was developed as a strategy for addressing doctoral wellbeing by reducing stress and anxiety associated with thesis writing. The new 
programme was implemented in 2017, and exploratory data gathered to evaluate the impact of the programme was gathered over the 2017/18 academic year. Specifically, this research aimed to address the following research questions:

1. Does participation in short writing workshops reduce doctoral students' anxiety or stress associated with writing?

2. How do doctoral students experience the writing support sessions and what do they perceive as being the value?

To both assess the impact of workshop participation on student perceptions of stress and anxiety, as well as explore the student experience of thesis writing support, we chose to adopt a mixed methods approach to this study. To answer the first research question, a survey was used to quantify changes in writing anxiety and associated levels of stress before and after attending structured or semi-structured workshop sessions. Subsequent focus group interviews allowed us to explore the student experience of thesis writing support more fully and address the second research question.

\section{The context for this research project}

This research project was conducted at a research-intensive UK university. Thesis in this context refers to the final doctoral level product submitted for assessment at the end of the doctoral degree. A series of writing support sessions were developed to support doctoral students from across the institution ranging from structured, to semi-structured, and completely unstructured sessions:

Structured Thesis Writing Workshops focused on the technical aspects of thesis writing as a genre, including appropriate structure, and writing style. Advice and guidance were provided by means of brief lectures. Participants were then able to put the advice into practice through specific writing exercises. Throughout these workshops, participants were encouraged to share their own experiences and disciplinary perspectives through group discussions. The workshops were facilitated by a learning developer with specific experience of developing writing skills and knowledge of diverse disciplinary approaches to writing. 
Semi-structured Writer's Block Workshops were less structured and focused on thesis writing as a process. The sessions were designed to prompt personal reflection followed by group discussion around key themes connected with overcoming writer's block. Sessions were facilitated by a UK Council for Psychotherapy (UKCP) accredited psychotherapist who focused on encouraging participants to reflect on their own practices and connect with their emotions. Participants were asked to identify and connect with their 'blocked' (i.e. non-writing) state and their ideal 'flow' (i.e. writing) state and toggle between them. Known in Neuro-Linguistic Programming as 'resource states', it was emphasised that each of these two states can have value to the writer (see Tosey and Mathison, 2009, for criticism of using positive psychology in isolation without balancing negative states and emotions). The desired, but elusive, 'flow' state in which the writer is performing comfortably and the words are literally flowing from their fingertips, was then used as a basis for discussion of suggested strategies. This mirrors the 'Miracle Question' used in Solution-Focused Brief Therapy (de Shazer and Dolan, 2012) to assist the client to visualise solutions to their presenting issue themselves. Having engaged participants with their emotions, the workshop also raised awareness of the symptoms of anxiety and depression and how to access support.

Unstructured Writing Retreats were developed as group writing retreats. With no formal instruction, these offered a protected time and space for writing in the company of others for mutual peer support. Writing retreats combined quiet, focused writing time, with regular breaks for informal chats and discussion with peers. The retreats were facilitated by a learning developer with experience of developing writing skills and an interest, but no qualifications, in supporting doctoral student wellbeing and mental health.

Each workshop or writing retreat session lasted three hours and together these formed a series of events that were offered over the course of a month each academic term, with an additional three writing retreats offered in November in conjunction with an academic writing festival. Doctoral students attending the sessions represented a wide range of discipline areas from across the institution and all stages of thesis writing from complete novice to near submission. 


\section{Survey methods}

The change in perceptions of wellbeing associated with writing was explored using an online survey sent to all participants who had booked onto the structured and semistructured writing support sessions during the 2017/18 academic year. Writing retreats had no pre-booking and so could not be included in this process. The survey questions were adapted from the Writing Process Questionnaire developed by Lonka et al. (2014) and the MedNord survey developed by Lonka et al. (2008). Specifically, we used the questions relating to writer's block and procrastination from the Writing Process Questionnaire and the questions relating to anxiety and stress from the MedNord survey. Each topic consisted of a set of statements, with participants rating their agreement with each statement on a scale from one to five. In addition, the pre-session survey included a set of monitoring questions including gender, native language and stage of degree as these are all factors thought to impact on writing anxiety (Huerta et al., 2016). All responses were downloaded to Excel for analysis and the average response for each topic calculated for each respondent.

All pre-session responses were used to explore any potential differences in wellbeing or writing motivation among participants before they attended the structured or semistructured workshops. Data were analysed by fitting a Linear Model with gender, language, and stage as fixed factors. We matched pre- and post-session responses, using only matched responses to explore the effects of participating in a writing support session. Next, data were analysed by fitting a Linear Mixed-Effects Model (LME) which accounts for the random effects associated with the response variable being repeated within subjects (Morrell, 1998). The model was fitted with workshop type and time (pre/post) as fixed factors and respondent as a random factor. The impact of each fixed factor was analysed using the Likelihood Ratio Test (Morrell, 1998). All statistical analyses were completed using $R$ version 3.5.0.

\section{Focus group interviews}

Invitations to participate in focus groups were sent to all 130 doctoral students who had participated in any thesis writing session over the 2017/18 academic year. Only 12 participants volunteered to take part, having participated in one or two writing support workshops each. Participants were organised into three focus groups to discuss: their 
perceptions of whether their expectations were met; whether they felt more confident about writing following the workshops; feelings they had during and after the workshops; and changes they would like to see made to the ways in which the workshops were organised. One of the project team facilitated the interviews and was observed by another colleague involved in the project for the purposes of researcher triangulation to record dynamics and enhance credibility of the process. Interviews were audio recorded and transcribed verbatim.

The transcribed focus group interviews were analysed using thematic analysis (Braun and Clarke, 2006). This approach provides a robust, systematic framework for coding qualitative data to identify patterns in relation to the research question and is used widely for health and wellbeing research (Braun and Clarke, 2014). Initial codes were assigned to sections of the transcripts and each code was checked and cross-referenced by other members of the research team to enhance credibility.

\section{Results and Discussion}

\section{Exploratory survey findings}

In total 29 participants from three structured sessions and 30 participants from two semistructured sessions were invited to participate in the online survey. Response rates were relatively low with only 23 participants responding to the pre-workshop survey. The majority of respondents were female (15 female, 8 male) in the middle of their degree ( 8 early, 11 middle, 4 late). Respondents were evenly split between native English speakers (11) and non-native English speakers (12). None of the tested factors (gender, stage of degree, language) explained any of the variation in responses to the questions on writer's block $\left(F_{4,18}=0.269, p=0.894\right)$, procrastination $\left(F_{4,18}=1.056, p=0.406\right)$ or anxiety $\left(F_{4,18}=\right.$ 1.326, $p=0.298$ ). Perceived stress levels did differ between some groups of participants $\left(F_{4,18}=4.962, p=0.007\right)$ with those in the middle of their degree reporting higher levels of stress than those early or late in their degree $(t=3.076, p=0.007)$. Non-native English speakers also reported lower levels of stress than native English speakers $(t=-2.343, p=$ $0.031)$.

Previous work has suggested that gender is a significant predictor of stress and poor mental health in doctoral students, with women reporting worse outcomes than men 
(Hargreaves et al., 2014; Guthrie et al., 2017). In this research we found no significant effect of gender on reported stress or anxiety levels. Instead, the stage of degree appeared to be a more significant explanatory factor. Among our participants, those in the middle of the degree reported higher levels of stress, perhaps suggesting that this is the stage in their studies when work-life balance is most challenging and work demands are high. Alternatively, it may be that by the end of their degree, students have developed coping mechanisms, increased skills, or increased confidence in their writing, and so report less anxiety associated directly with writing. Certainly, the experiences shared by interviewees in Morris et al. (2015) show how much of a rollercoaster the PhD journey can be, and the skills and coping mechanisms doctoral students build along the way. Future research might usefully explore further how the areas of stress, and therefore the specific types of support needed, change through the doctoral journey.

Only 16 respondents could be matched with pre- and post- session responses (nine from the structured thesis writing sessions; seven from the semi-structured writer's block sessions). Participants reported a positive response to all measured variables when comparing pre-session to post-session survey responses. Participants reported a big impact on their perceived writer's block $\left(\mathrm{X}_{2}=7.268, \mathrm{p}=0.007\right)$ and procrastination $\left(\mathrm{X}_{2}=\right.$ 8.791, $p=0.003)$ while the impact on their sense of wellbeing such as anxiety $\left(X_{2}=4.017\right.$, $p=0.045)$ and stress $\left(X_{2}=2.917, p=0.088\right)$ was less pronounced. Workshop type was not a significant explanatory factor for any of the measured response variables $(p>0.1$ for all factors) suggesting that both workshop types had positive impacts on perceived levels of stress and anxiety.

One aspect of these benefits may be increasing confidence. In particular, the structured thesis sessions focus on clarification of expectations which should give participants confidence in their ability to meet those expectations. Such structured writing courses have been shown to improve both confidence in and knowledge of academic writing (Crisfield, 2020). As suggested by Guthrie et al. (2017), confidence in abilities should reduce perceived stress and anxiety around completing the task. The use of Solution-Focussed Brief Therapy (SFBT) used by the trained psychotherapist delivering the semi-structured writer's block workshops may account for why some participants felt that they were of benefit. Meta-analysis of the SFBT technique shows that it is has a slight effect on improving internalising (i.e. depressive) behaviours (Kim, 2007). However, it cannot be 
claimed that the benefits to participants were restricted to those who participated in that particular form of workshop alone, or that it was the SFBT element of the eclectic therapeutic approach used in that workshop that made the most difference. Both workshop types were seen to be equally beneficial in improving quantitative measures of writing anxiety and stress. Perhaps the main benefit of both workshop types may have emerged from shifting the focus of thesis writing from the final product to the thesis as an ongoing developmental process. As shown by Stubb, Pyhältö and Lonka (2012), those who see the thesis as a process report better wellbeing and study engagement. Although the facilitators of the two different workshops may have approached workshop facilitation differently, both were focused on empowering participants to find their own solutions and strategies for thesis writing.

\section{Focus group themes}

As the survey shows, participating in short writing sessions can reduce students' writing related anxiety and improve their overall productivity and wellbeing as a result. Following up the survey with focus group interviews, we found that interviewees identified many benefits from engaging with the workshops. These benefits can be encapsulated in three themes discussed below: 'tangible benefits', 'supportive environment' and 'empowerment'.

\section{Theme 1: Tangible benefits}

As the survey showed, workshop participation reduced the stress and anxiety students had around writing. Doctoral students are juggling many conflicting demands on their time which adds to their sense of stress, and means that workshop participation is often not prioritised (Saetnan, 2020). Our research indicates that participation in thesis writing workshops and writing retreats, rather than being considered an added demand on their time and an added source of stress, is a valuable strategy for reducing stress and anxiety associated with thesis writing. One way in which these workshops provide value for participants is in the explicit tips and tricks for writing and productivity as highlighted by our participants such as changing working habits, creating a writing plan and tips for being more productive: 
And tips on how to stop procrastinating. I thought that was very useful because it made, it kind of put in perspective that not everyone is always on top of things all the time, so that was kind of reassuring.

it made me aware, just forget about revising and write for as long as you feel comfortable and then come back and revise and put it the way you like it.

There were notable differences in perceived benefits for individuals, showing that students took away their own unique strategies and thoughts about writing which were relevant to their personal practice:

like a very practical thing of benefit to me, so it wasn't generic to everybody, it was like this is personal to me, this is personal to my thesis, and for the next two weeks, I know what I am doing, and so that was really good.

All workshop formats encouraged the sharing and open discussion of personal strategies and approaches to writing. A positive consequence and learning technique mentioned by some was the power of learning through teaching and explaining the process to others and they felt that the workshops had helped them in this regard:

I am doing some tutoring so I actually explain to others how to write, and being on the other side of the table, sometimes really helps.

Interviewees expressed a desire to find the motivation to write, as well as reassurance with regards to their writing abilities. Some individuals describe how they went with the expectation of developing their motivation, and despite this being the case, for some it failed to create a sustained effect:

I am looking for, to take, to take something for motivation, perhaps some knowledge, but mostly the motivation to write [...] Some workshops they keep your motivation for a week, or two weeks, but never for a month unfortunately. 
Aspects of the academic journey are often unclear, with a hidden curriculum which is never explicitly stated (Starke-Meyerring, 2011). This sense of mystery or unknown, combined with the high stakes of thesis writing, can be a great source of stress and anxiety for doctoral students. Workshops such as those discussed here are an opportunity to make some of these hidden expectations explicit, and to demystify the thesis or writing process through conversations with peers and experienced writers (Samuels, Deane and Griffin, 2012; Foot, 2017; Crisfield, 2020) and thereby allay the fears and anxiety of participants. Having a set of tangible tools and strategies to implement can therefore be reassuring.

Although understanding the final product is helpful, it is interesting to note that some of these tangible benefits identified by participants are in the form of strategies for managing the writing as a process rather than the end product. Problems in scientific writing, such as blocks and procrastination, perfectionism, and seeing writing as an innate ability are all negatively related to productivity (Lonka et al., 2014). A focus of both the structured and semi-structured workshop sessions was to provide tools and strategies for overcoming these challenges, but also aim to change participants' perceptions of writing; to help them recognise that writing is a skill that can be improved through practice. As indicated by this participant, we did achieve this for some - they felt it had altered their whole approach to the writing process:

...the biggest difference, because I think that that has probably changed my psyche a bit, about writing, and I think that has helped... the freewriting one was the one that had made the biggest impact...that is just a good way of writing and thinking.

As Stubb, Pyhältö and Lonka (2012) suggest, seeing the thesis as a learning process rather than focusing on the end product is associated with better wellbeing and lower levels of anxiety around writing. What we cannot know from these results are whether those who choose to participate in our workshops do so because they already see the thesis as a writing process and are looking for tools to manage the process, or whether the workshop changes participants' initial perception of thesis writing. This is perhaps something worth exploring further in future. 


\section{Theme 2: Supportive environment}

Being surrounded by supportive peers also impacted on participants' sense of wellbeing. Several participants brought up aspects of the workshop environment as crucial to workshop success and benefit, related both to the physical aspects of the workshop environment, and to the social dimension created by the participants and the facilitator during the session. In a very physical sense, being taken out of your normal working environment was beneficial, removing the usual distractions and providing a welcome change:

It was off campus but that was quite nice in a way, because it meant you, you were a bit removed, you know like I'm in uni and I'm here it's a bit like well you doing something different and you're sitting down and writing kind of thing.

This aspect of the working environment was particularly highlighted in relation to the writing retreats which offered a diversion from their routine and usual environment with an unanticipated consequence of feeling a social group pressure to be productive which gave them a motivation to write as everyone else was doing it. Being part of the group gave them an impetus to work and a focus that they sometimes lacked on their own:

That competitiveness I think, you don't want to look like you're the lazy one who's not doing it if everyone else around you is doing it. So you think, well, sort of as I'm here I may as well do something.

All workshops were generally viewed as an opportunity to share in some way, with peer discussion an explicit pedagogic tool used by all facilitators. Participants felt that they offered some sense of community and a chance to share concerns and discuss writing:

Then sometimes um there'd be more general discussions on well what people do more generally to motivate themselves to write, what's stopping you from writing, um so there was sort of little discussions in between which is helpful as well. 
There was a feeling that being surrounded by others who were in a similar position gave a sense of belonging that was reassuring. Other interviewees reported that it was helpful to be able to talk with others who were at different stages of their degree and for some, the workshops generated lasting connections:

We actually ended up working together and meeting after work for, talking about science, or having a drink...one boy and a girl, they are still my friends nowadays, after three years.

Talking to others in similar situations can be encouraging (Crisfield, 2020) and thus act as a form of stress management. Doctoral students are looking for opportunities for social engagement with fellow students and recognising the value of these social interactions to improve their own wellbeing (Saetnan, 2020). Knowing that you are not alone, and finding companionship among peers, can be great motivation and inspiration for productivity as others have also found (Oluwole et al., 2018; Noone and Young, 2019; Tyndall et al., 2019) and this improved productivity can be reassuring, reducing the sense of stress or anxiety associated with thesis writing and hence improve wellbeing.

One key aspect of this supportive environment is that it opens up spaces for conversations about writing, which can turn into valuable learning opportunities that help participants to articulate implicit theories and beliefs, and test out professional knowledge or practice in a safe space (Haigh, 2005). For many academics, the process of writing is never shared or explicitly discussed (Starke-Meyerring, 2011). Talking about writing not only provides tangible benefits as discussed above, it potentially also makes writing a more meaningful and manageable activity and improves people's experiences of writing (Murray, 2015). This dialogic pedagogy was incorporated explicitly in both the structured and semistructured workshop sessions and became an important feature of the writing retreats through the serendipitous conversations in the writing breaks.

\section{Empowerment}

Indicative of the stress and anxiety highlighted in the pre-workshop surveys, some interviewees described the process of writing as overwhelming. However, the workshops helped them feel as though they were in control, thereby reducing their stress levels: 
I guess it sort of makes you think about writing, as like, it can be easy to get overwhelmed by the amount that you've got to do... because it's a lot and there's no way of getting over that a PhD is, at the end of the day, a hell of a lot of writing. I think it has had an impact on my stress levels.

Feeling in control of their own writing process can be both powerful and empowering considering the fraught and confusing journey that thesis writing can be. Part of that sense of empowerment can be having confidence in their own skills. As discussed in the first theme, workshops provided specific skills and strategies which gave a sense of confidence. However, for some more experienced doctoral students, they felt that the workshops merely reinforced some principles they already knew. This experience was still beneficial as validation of current skills, and for some the experience surfaced strategies and knowledge that were latent in their consciousness:

It was something that was common sense. It was something that I already knew but I wasn't fully aware ... er, but something that I didn't proactively know or had in the back of my mind

Another related aspect of this theme was freedom. The workshops were experienced as a safe space to experiment and try new things without fear of judgement, and this sense of freedom can be empowering. Free writing was a deliberate strategy incorporated into some workshops, most notably the semi-structured writer's block sessions, and several participants noted this as a valuable strategy:

So we had five minutes of just writing or whatever was in our head, get something down on paper, erm, and I find that quite fascinating because I think I am a bit of a perfectionist when it comes to writing, so if I write a sentence I will go back to correct the grammar, you know l'll think it over and I'll over criticise it.

This theme highlights the value of workshops as a space to experiment and take control of the participants' own personal writing process. Becoming an academic is in large part about finding your own voice; and doing so in negotiation with the expectations of 
supervisors and colleagues in the discipline. This negotiation involves recognising and adapting to tacit disciplinary expectations, which are rarely, if ever, openly discussed, and such negotiation requires confidence. Talking about research and research processes, such as writing, with others becomes an opportunity to validate doctoral students' own identity as researchers (Mantai, 2017). The interdisciplinary nature of these workshops may have the added benefit of empowering participants to become proponents of their own discipline through dialogue across disciplines (Cuthbert, Spark and Burke, 2009).

Building on the previous two themes, gaining specific skills or tools is one element of building confidence. Discussing ideas, strategies and fears with colleagues and peers is another element of building confidence. Together these empower participants to experiment and take control of their own writing journey. By developing a sense of confidence and feeling in control of their own writing journey, we can reduce anxiety and stress related to the thesis, specifically, or academic writing more generally. By gaining confidence and a sense of self-efficacy, participants' motivation for writing and their writing outcomes are likely to improve (Pajares, 2003). In this way, we can improve the wellbeing of doctoral students by empowering them to take control of their own wellbeing through managing the writing process.

\section{Conclusions}

Our exploratory survey suggests that participating in even short writing workshops can have a positive impact on doctoral students' wellbeing by reducing their perceived levels of writing related stress and anxiety. Participants appreciated how workshops offered tools and techniques for managing the writing process as well as a space to explore and discuss writing with peers in a supportive environment. The sense of empowerment and confidence which comes from these brief interactions can be very valuable for improving wellbeing of doctoral students. Although using different strategies or facilitation techniques, all workshop types explored here provided valuable opportunities for students to connect with peers and discuss challenges and strategies in an open and supportive environment.

A few participants noted that they remained in contact with peers from the writing retreats and continued to write together after the workshop. In this project we were limited to exploring only the immediate impact of workshop attendance on stress and anxiety 
associated with thesis writing. Further research is therefore suggested to explore how to foster more sustained impacts on participants beyond the workshop, and whether this longer-term peer support has lasting impacts on participants' wellbeing.

\section{References}

Aitchison, C. (2009) 'Writing groups for doctoral education', Studies in Higher Education, 34(8), pp. 905-916. doi:10.1080/03075070902785580.

Aitchison, C. and Lee, A. (2006) 'Research writing: problems and pedagogies', Teaching in Higher Education, 11(3), pp. 265-278. doi: 10.1080/13562510600680574.

Badenhorst, C. (2018) 'Graduate student writing: complexity in literature reviews', Studies in Graduate and Postdoctoral Education, 9(1), pp. 58-74. doi: 10.1108/SGPE-D-1700031.

Bærenholdt, J. O., Gregson, N., Everts, J., Granås, B. and Healey, R. L. (2010) 'Performing academic practice: using the master class to build postgraduate discursive competences', Journal of Geography in Higher Education, 34(2), pp. 283-298. doi: 10.1080/03098260903502695.

Beasy, K., Emery, S., Dyer, L., Coleman, B., Bywaters, D., Garrad, T., Crawford, J., Swarts, K. and Jahangiri, S. (2020) 'Writing together to foster wellbeing: doctoral writing groups as spaces of wellbeing as spaces of wellbeing', Higher Education Research \& Development. Taylor \& Francis, 39(6), pp. 1091-1105. doi: 10.1080/07294360.2020.1713732.

Boud, D. and Lee, A. (2007) "'Peer learning" as pedagogic discourse for research education', Studies in Higher Education, 30(5), pp. 501-516. doi: $10.1080 / 03075070500249138$.

Braun, V. and Clarke, V. (2006) 'Using thematic analysis in psychology', Qualitative Research in Psychology, 3(2), pp. 77-101. doi: 10.1191/1478088706qp063oa. 
Braun, V. and Clarke, V. (2014) 'What can "thematic analysis" offer health and wellbeing researchers?', International Journal of Qualitative Studies on Health and Well-being, 9, pp. 9-11. doi: 10.3402/qhw.v9.26152.

Burgoine, T., Hopkins, P., Rech, M. F. and Zapata, G. P. (2011) “'These kids can't write abstracts": Reflections on a postgraduate writing and publishing workshop', Area, 43(4), pp. 463-469. doi: 10.1111/j.1475-4762.2011.01030.x.

Ciampa, K. and Wolfe, Z. (2019) 'Preparing for dissertation writing: doctoral education students' perceptions', Studies in Graduate and Postdoctoral Education, 10(2), pp. 86-108. doi: 10.1108/SGPE-03-2019-0039.

Cotterall, S. (2011) 'Doctoral students writing: where's the pedagogy?', Teaching in Higher Education, 16(4), pp. 413-425. doi: 10.1080/13562517.2011.560381.

Crisfield, M. (2020) 'Making the transition to master's dissertation writing: evaluating the impact of a dissertation writing course on PGT students' confidence', Journal of Learning Development in Higher Education, 17. Available at: https://journal.aldinhe.ac.uk/index.php/jldhe/article/view/561 (Accessed 4 July 2020).

Cuthbert, D., Spark, C. and Burke, E. (2009) 'Disciplining writing: the case for multidisciplinary writing groups to support writing for publication by higher degree by research candidates in the humanities, arts and social sciences', Higher Education Research \& Development, 28(2), pp. 137-149. doi: 10.1080/07294360902725025.

Delyser, D. (2003) 'Teaching graduate students to write: a seminar for thesis and dissertation writers', Journal of Geography in Higher Education, 27(2), pp. 169-181. doi: 10.1080/03098260305676.

Evans, T. M., Bira, L., Gastelum, J. B., Weiss, L. T. and Vanderford, N. L. (2018) 'Evidence for a mental health crisis in graduate education', Nature Biotechnology, 36, pp. 282-284. doi: 10.1038/nbt.4089. 
Fergie, G., Beeke, S., McKenna, C. and Creme, P. (2011) “'It's a Lonely Walk”: supporting postgraduate researchers through writing', International Journal of Teaching and Learning, 23(2), pp. 236-245.

Ferguson, T. (2009) 'The "write" skills and more: a thesis writing group for doctoral students', Journal of Geography in Higher Education, 33(2), pp. 285-297. doi: 10.1080/03098260902734968.

Foot, R. E. (2017) 'It's not always what it seems': exploring the hidden curriculum within a doctoral program. Kent State University College.

Guthrie, S., Lichten, C., van Belle, J., Ball, S., Knack, A. and Hofman, J. (2017) Understanding mental health in the research environment: A Rapid Evidence Assessment. Available at:

https://royalsociety.org/ /media/news/2017/understanding-mental-health-in-theresearch-environment.PDF (Accessed 4 July 2020).

Haigh, N. (2005) 'Everyday conversation as a context for professional learning and development', International Journal for Academic Development, 10(1), pp. 3-16. doi: 10.1080/13601440500099969.

Hargreaves, C. E., De Wilde, J. P. and Walsh, E. (2014) Re-evaluating doctoral researchers' well-being: what has changed in five years? Available at: https://www.imperial.ac.uk/media/imperial-college/study/graduateschool/public/well-being/Wellbeing-for-GS.pdf (Accessed 4 July 2020).

HEFCE (2010) Research degree qualification rates. Available at: www.hefce.ac.uk (Accessed 4 July 2020).

Huerta, M., Goodson, P., Beigi, M. and Chlup, D. (2016) 'Graduate students as academic writers: writing anxiety, self-efficacy and emotional intelligence', Higher Education Research \& Development, 4360(October), pp. 1-14. doi: 10.1080/07294360.2016.1238881. 
Hunter, K. H. and Devine, K. (2016) 'Doctoral students' emotional exhaustion and intentions to leave academia', International Journal of Doctoral Studies, 11, pp. 3561. Available at: http://ijds.org/Volume11/IJDSv11p035-061Hunter2198.pdf (Accessed 4 July 2020).

Johnson, E. M. (2018) 'The doctoral writing conversation: establishing a generic doctoral writing programme', Open Review of Educational Research, 5(1), pp. 16-27. doi: 10.1080/23265507.2017.1419439.

Kim, J. S. (2007) 'Examining the effectiveness of solution-focused brief therapy: a metaanalysis', Research on Social Work Practice, 18(2), pp. 107-116. doi: 10.1177/1049731507307807.

Levecque, K., Ansel, F., De Beuckelaer, A., Van der Heyden, J. and Gisle, L. (2017) 'Work organization and mental health problems in PhD students', Research Policy. Elsevier B.V., 46(4), pp. 868-879. doi: 10.1016/j.respol.2017.02.008.

Lonka, K. (2003) 'Helping doctoral students finish their theses', in Björk, L. et al. (eds) Teaching academic writing across Europe. Dordrecht: Kluwer University Press, pp. 113-131.

Lonka, K., Sharafi, P., Karlgren, K., Masiello, I., Nieminen, J., Birgegård, G. and Josephson, A. (2008) 'MED NORD--A tool for measuring medical students' wellbeing and study orientations', Medical Teacher, 30(1), pp. 72-79. doi: 10.1080/01421590701769555.

Lonka, K., Chow, A., Keskinen, J., Hakkarainen, K., Sandström, N. and Pyhältö, K. (2014) 'How to measure PhD students' conceptions of academic writing - and are they related to well-being?', Journal of Writing Research, 5(3), pp. 245-269.

Mackie, S. A. and Bates, G. W. (2019) 'Contribution of the doctoral education environment to PhD candidates' mental health problems: a scoping review', Higher Education Research and Development, 38(3), pp. 565-578. doi:

10.1080/07294360.2018.1556620. 
Maher, D., Seaton, L., McMullen, C., Fitzgerald, T., Otsuji, E. and Lee, A. (2008) "Becoming and being writers": The experiences of doctoral students in writing groups', Studies in Continuing Education, 30(3), pp. 263-275. doi: 10.1080/01580370802439870.

Mantai, L. (2017) 'Feeling like a researcher: experiences of early doctoral students in Australia', Studies in Higher Education, 42(4), pp. 636-650. doi: 10.1080/03075079.2015.1067603.

Metcalfe, J., Wilson, S. and Levecque, K. (2018) 'Exploring wellbeing and mental health and associated support services for postgraduate researchers', (May). Available at: www.vitae.ac.uk (Accessed 4 July 2020).

Morrell, C. H. (1998) 'Likelihood Ratio Testing of Variance Components in the Linear Mixed-Effects Model Using Restricted Maximum Likelihood', Biometrics, 54(4), pp. 1560-1568. doi: 10.2307/2533680.

Morris, C., Wisker, G., Cheng, M., Lily, J., Warnes, M., Robinson, G. and Trafford, V. (2015) 'Wellbeing and the research student', in Marshall, L. and Morris, C. (eds) Taking wellbeing forward in higher education: reflections on theory and practice. University of Brighton Press, pp. 72-83.

Murray, R. (2015) Writing in social spaces: a social processes approach to academic writing. Abingdon, Oxon: Routledge.

Muurlink, O. and Poyatos Matas, C. (2011) 'A higher degree of stress: academic wellbeing', in Marshall, L. and Morris, C. (eds) Taking wellbeing forward in higher education: reflections on theory and practice. University of Brighton Press, pp. 6071.

Noone, J. and Young, H. M. (2019) 'Creating a community of writers: participant perception of the impact of a writing retreat on scholarly productivity', Journal of Professional Nursing, 35(1), pp. 65-69. doi: 10.1016/j.profnurs.2018.07.006. 
Oluwole, D. O., Achadu, O., Asfour, F., Chakona, G., Mason, P., Mataruse, P. and McKenna, S. (2018) 'Postgraduate writing groups as spaces of agency development', South African Journal of Higher Education, 32(6), pp. 370-381. doi: 10.20853/32-6-2963.

Pajares, F. (2003) 'Self-Efficacy Beliefs, Motivation, and Achievement in Writing: a Review of the Literature', Reading \& Writing Quarterly, 19(2), pp. 139-158. doi: $10.1080 / 10573560308222$.

Paltridge, B. (2016) 'Writing retreats as writing pedagogy', Writing \& Pedagogy, 8(1), pp. 199-213. doi: 10.1558/wap.v8i1.27634.

Panger, G. (2015) Graduate student happiness \& well-being report. Available at: http://ga.berkeley.edu/wellbeingreport/ (Accessed 4 July 2020).

Papen, U. and Theriault, V. (2018) 'Writing retreats as a milestone in the development of PhD students' sense of self as academic writers', Studies in Continuing Education, 40(2), pp. 166-180. doi: 10.1080/0158037X.2017.1396973.

Saetnan, E. R. (2020) 'Graduate students ' motivations for participating in development workshops', Practice and Evidence in the Scholarship of Teaching and Learning in Higher Education, 14(1), pp. 117-136.

Samuels, P., Deane, M. and Griffin, J. (2012) 'Report on postgraduate training event in science education writing', Journal of Learning Development in Higher Education, 4. Available at: https://journal.aldinhe.ac.uk/index.php/jldhe/article/view/134 (Accessed 4 July 2020).

de Shazer, S. and Dolan, Y. (2012) More than miracles: the state of the art of solutionfocused brief therapy. Abingdon: Routledge.

Starke-Meyerring, D. (2011) 'The paradox of writing in doctoral education: student experiences', in Doctoral Education: Research-Based Strategies for Doctoral 
Students, Supervisors and Administrators. Springer Netherlands, pp. 75-95. doi: 10.1007/978-94-007-0507-4.

Stubb, J., Pyhältö, K. and Lonka, K. (2012) 'The experienced meaning of working with a PhD thesis', Scandinavian Journal of Educational Research, 56(4), pp. 439-456. doi: 10.1080/00313831.2011.599422.

Tosey, P. and Mathison, J. (2009) Neuro-linguistic programming: a critical appreciation for managers and developers. Palgrave Macmillan UK. doi: 10.1057/9780230248311.

Tyndall, D., Forbes III, T. H., Avery, J. and Powell, S. B. (2019) 'Fostering scholarship in doctoral education: using a social capital framework to support PhD student writing groups', Journal of Professional Nursing, 35(4), pp. 300-304. doi:

10.1016/j.profnurs.2019.02.002.

Vitae (2020) PGR Catalyst Fund resources. Available at: https://www.vitae.ac.uk/doingresearch/wellbeing-and-mental-health/catalyst-project-resources-1 (Accessed: 21 August 2020).

Wellington, J. (2010) 'More than a matter of cognition: an exploration of affective writing problems of post-graduate students and their possible solutions', Teaching in Higher Education, 15(2), pp. 135-150. doi: 10.1080/13562511003619961.

Wilmot, K. (2018) 'Designing writing groups to support postgraduate students' academic writing: a case study from a South African university', Innovations in Education and Teaching International, 55(3), pp. 257-265. doi: 10.1080/14703297.2016.1238775.

\section{Author details}

Charles A. Buckley is a Senior Academic Developer at the University of Liverpool. Charles is a National Teaching Fellow and Principal Fellow with Advance HE. He has a number of research interests including the use of visual representation in research, 
learning and teaching, lecturer identities and perceptions of continuing professional development and the use of grounded theory in qualitative research.

Eli R. Saetnan is a Senior Academic Developer at The University of Liverpool, supporting the scholarship and teaching development of early career researchers. Her main research interest is in the impact of academic development on the academic practices and confidence development of novice academics.

Amelia Gerber participated in this project as part of her Masters in Psychology Research Methods.

Joanna Cheetham is a Senior Educational Developer in the Centre for Innovation in Education at the University of Liverpool. She is particularly interested in compassionate pedagogies and inclusive curriculum design.

Tom A. R. Price is a Senior Lecturer in Evolutionary Biology at the University of Liverpool. His main focus is the impact of climate change on fertility, but he also works to develop resources to support wellbeing and good mental health in PhD students and the wider university community.

Jenna Kenyani is Public Engagement Officer and PGR wellbeing Advisor for the Faculty of Health and Life Sciences. She is a mental health advocate and has an interest in supporting both students and staff in their wellbeing.

Alan M. Greaves is a Senior Lecturer in Archaeology at the University of Liverpool. Alan is a National Teaching Fellow, a Principal Fellow with Advance HE, and an accredited psychotherapist registered with the UK Council for Psychotherapy (UKCP). His pedagogic and therapeutic interests include Writer's Block, Post-Traumatic Stress Disorder (PTSD) and LGBT mental health and inclusion in Higher Education. 